\title{
Violence Against Women in Politics on Twitter
}

\section{A Micro-Analysis}

Gendered negativity attacks a person's gender identity to make the victim feel inferior. These attacks reenforcing gender norms and patriarchal ideologies. Women in politics, especially those who hold positions of high visibility, face a significant amount of gendered negativity compared to their male counterparts. Gendered negativity against women in politics can discourage women from pursue public office and other leadership positions.

\section{How was the study conducted?}

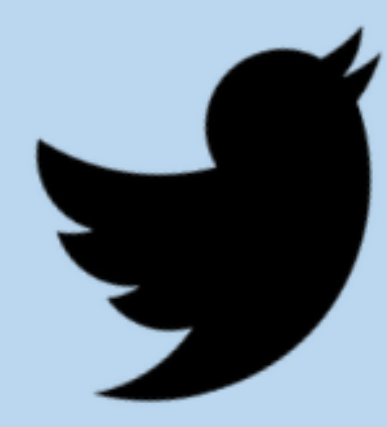

Manually scrapped tweets by federal ministers that referenced women in politics. Manually scrapped the replies of the tweets. Coded the replies of the original tweet for gendered remarks to understand gendered attacks women in cabinet receive.

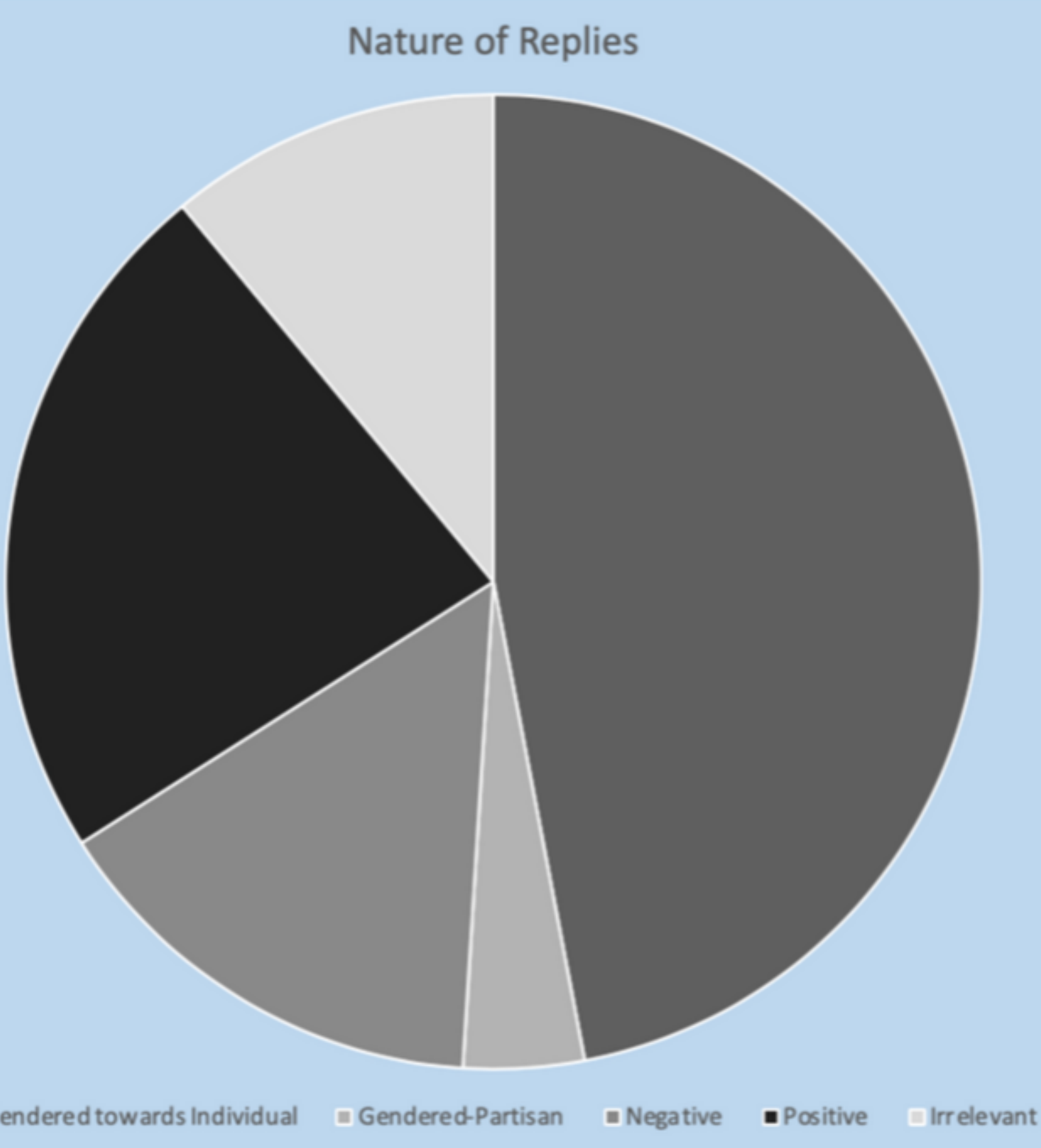

For more information on gendered attacks toward women in politics on social media:

https://theconversation.com/green-with-rage-womenclimate-change-leaders-face-online-attacks-123155

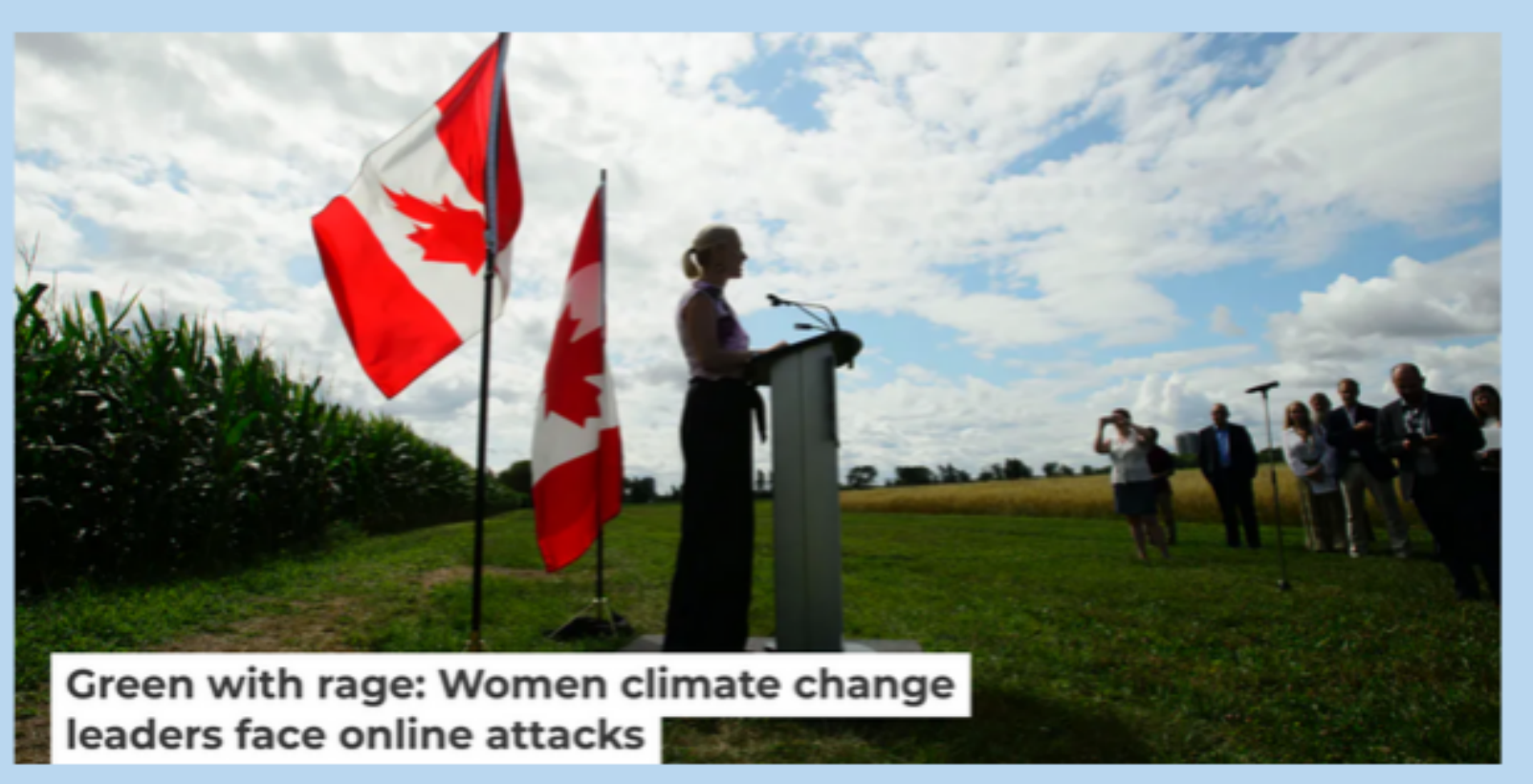

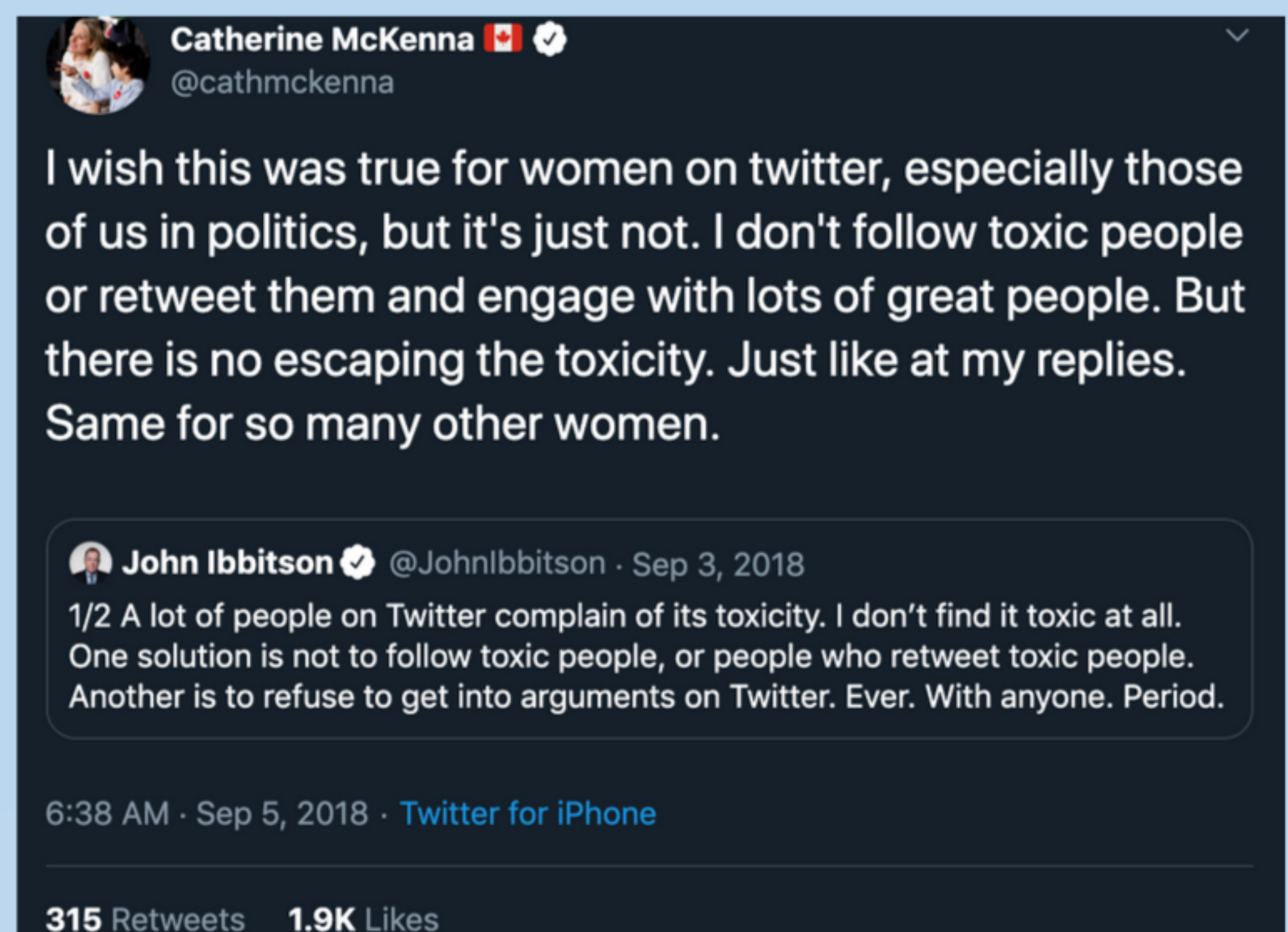

450 replies on the original tweet 163 replied were removed 131 replies contained gendered attacks

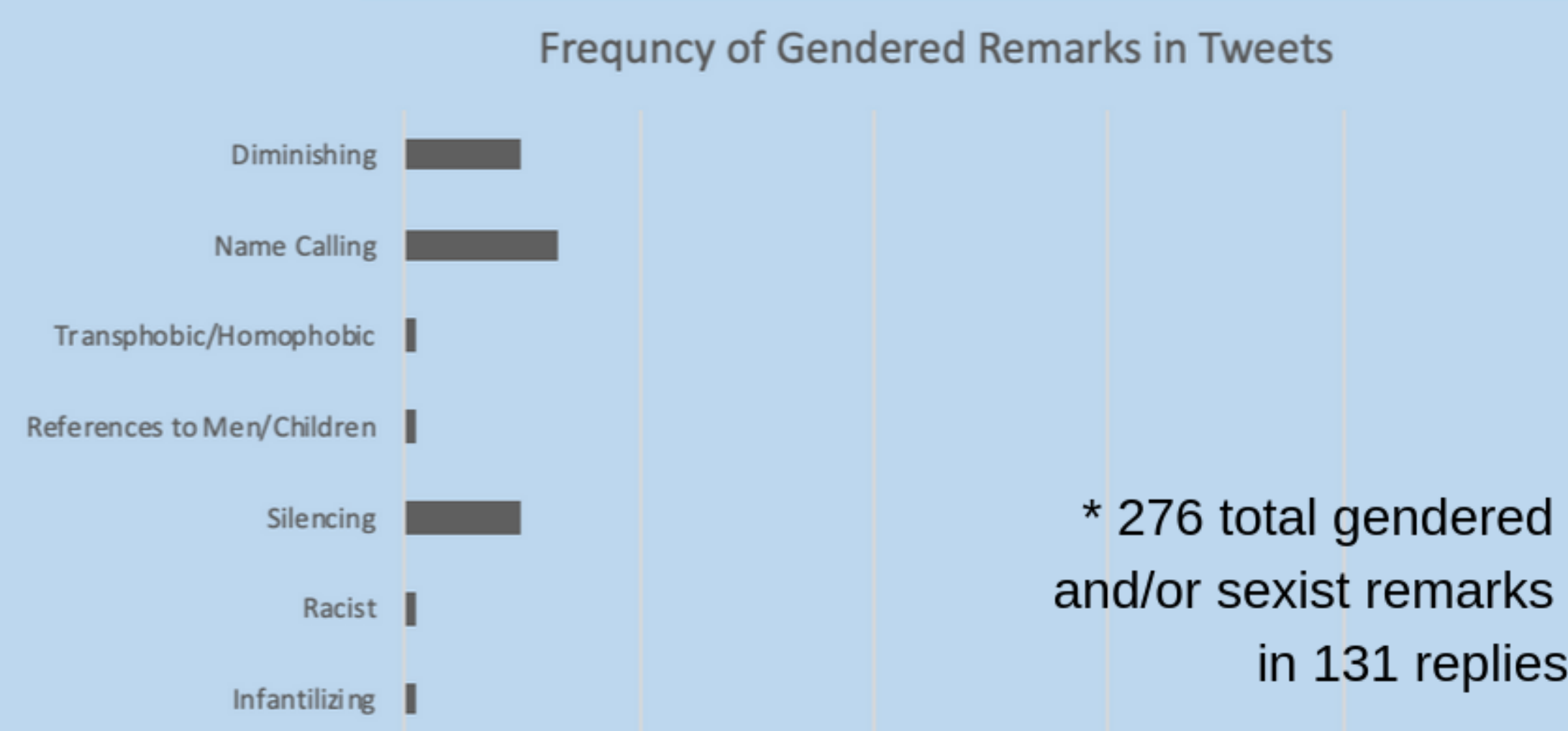

Feminist Denier $5 /$ Men To

Physical appearance $\square$

Weak/Victim-blaming

Incompetence/stupidity
40

- Frequncy of Gendered Remarks in Tweets 